Article

\title{
A Narrative-Driven Role-Playing Game for Raising Flood Awareness
}

\author{
Fotios Spyropoulos ${ }^{1}$, Ioannis Trichakis ${ }^{2, *}$ and Anthi-Eirini Vozinaki ${ }^{1}$ \\ 1 School of Chemical and Environmental Engineering, Technical University of Crete, 73100 Chania, Greece; \\ fspyropoulos@isc.tuc.gr (F.S.); avozinaki@isc.tuc.gr (A.-E.V.) \\ 2 European Commission, Joint Research Centre (JRC), 21027 Ispra, Italy \\ * Correspondence: ioannis.trichakis@ec.europa.eu
}

Citation: Spyropoulos, F.; Trichakis, I.; Vozinaki, A.-E. A Narrative-Driven Role-Playing Game for Raising Flood Awareness. Sustainability 2022, 14 554. https://doi.org/10.3390/ su14010554

Academic Editor: Sara Catalán Gil

Received: 7 December 2021

Accepted: 3 January 2022

Published: 5 January 2022

Publisher's Note: MDPI stays neutral with regard to jurisdictional claims in published maps and institutional affiliations.

Copyright: (c) 2022 by the authors. Licensee MDPI, Basel, Switzerland. This article is an open access article distributed under the terms and conditions of the Creative Commons Attribution (CC BY) license (https:// creativecommons.org/licenses/by/ $4.0 /)$.

\begin{abstract}
In the framework of a water resources management class in the Technical University of Crete, a narrative-driven role-playing game (RPG) was planned and tested in the classroom, with the intent to raise awareness among the students on how floods can have an impact on the everyday lives of different citizens. During this game, the students had the opportunity to act as different stakeholders. In order to assess the impact of this game on participants' thoughts of who might be affected by a flood event, two questionnaires were used, one before and one after the game. The results show that there was very positive feedback from the participants on how this RPG helped them realize the different implications a flood event might have on citizens and decision makers. The community-based aspect that was chosen for this RPG implementation showed the difficulties the specific roles would face as single individuals and as a community in general. Using a similar approach can help any stakeholder understand the challenges in a more direct way than with traditional lecturing and presentations.
\end{abstract}

Keywords: gamification; awareness; teaching; stakeholders; communal; flood risk; flood management

\section{Introduction}

This work details the creation of and reports the findings from applying a role-playing game (RPG) within the framework of a water resources management class. It was viewed as an alternative means of teaching students the risks associated with floods and the several aspects they need to consider when managing such an event. The setting was in a classroom of the Technical University of Crete, during the Water Resources Management class. Due to COVID-19 related restrictions, the initial plan to play the game in the physical classroom changed to a virtual classroom. Nevertheless, in order to avoid the alienation and sense of isolation of a virtual classroom, all participants had, during the whole game, both cameras and microphones on and were encouraged to behave as they would in a physical classroom.

\subsection{Literature Review}

It has been well established that role-playing games as "serious games" can be useful tools in increasing awareness and engagement regarding complex issues, such as climate change or flood management [1]. Serious games can raise awareness and educate nonscientific audience on complex matters such as flood management [2]. Many serious games are discourse-based problem solving quite similar to the format of RPGs. Because of the flexibility of the genre, it has been implemented in multiple levels of education; in elementary school in which the main focus was raising awareness and preparing the students for a flood, while monitoring the success of the process with multiple questionnaires [3]. Likewise, in high schools, role-playing games were constructed with debating in mind in the context of climate change lessons. In this kind of role-playing game, groups of students, with different backgrounds in their respective field of study, were given roles in forms of cards and would converse with each other about a given scenario [4]. In addition, it has 
been suggested that the implementation of gamified aspects in the teaching process has been successful in the field of student engagement, which might refer to gamified quizzes and not a full game [5]. There is also application regarding stakeholder engagement in communities, as video game RPGs have shown promising results. An RPG has been developed with a focus on training decision makers in crises related to weather hazards; it is in a way similar to the game design in this paper but emphasizes more the part of management and precautionary measures [6]. Moreover, a previously developed game [7] aimed to increase awareness on matters regarding household consumption of food, water, and energy and investigate climate change effects. It has been designed as an inclusive space for stakeholders (utility companies, governance, and local communities) with the intention of transferring academic knowledge to practitioners. An RPG can be more targeted and deliberate in its design and audience. For example, in a previous study, a video game was designed in order to raise awareness of flood risk, with the intended audience of local communities of fish farmers. Because of the inherent need for quantification when facing the concept of risk, the game was focused more on strategy creation and an experiential understanding of flood risk through trial and error while playing the game [8]. Games can be designed with a broader intended audience but with a specific subject or combination of subjects in mind, such as flood management and cultural heritage [9]. Regarding stakeholder engagement, it is suggested that an RPG setting may be more effective, in comparison with other standard ways of engaging with the public, in part because of its informal atmosphere. In the current study, the game was conversation-based with an inclusion of a map of said area and cards that had role assignments. The success of the game was monitored by a pre-game and a post-game questionnaire [9]. A game about farmers in Brazil operated in a similar mindset, on the basis of social learning and collective action with focus on increasing awareness on food security, building resilience, and adapting to climate change, from the perspective of climate smart agriculture [10]. In same spirit of community engagement, a tabletop board game was developed with the goal of exploring the relational effectiveness of water governance from conflicting stakeholder [11]. In general, such complex issues can be workshopped from an RPG to a bottom-up policymaking process; the players as stakeholders can come into conflict, and through the playing process, they can be empowered and engaged as a community. This suggests that RPGs, as awareness raising and community action tools, can find applications in wide varieties of contexts, situations, and scales $[12,13]$. In our work, the RPG was used to raise awareness among students and help them discover the complexity of flood risk and flood management issues in a university class environment, but this could easily be replicated in different environments with other set of stakeholders.

This study focused more on how the RPG can be used for educational purposes and on the social aspect. Letting participants realize the impact of the different personal views on community operation during a flood event, enables participants to understand the complexity and obtain a holistic overview of this complex issue.

\subsection{Selection of Game Genre}

The success of gamification is relative to the engagement of the learner/player, which is primarily enforced by game mechanics and aesthetics [14]. Given the recent increase in the number and quality of niche games with semi-educational aspects and game literacy among a wider demographic, gamification has been linked with videogames. Although videogames can be hyperrealistic simulations with exact physics and solid rules, their scripted nature can be constraining as educational tools in subjects that demand a greater amount of input from the players. A key concept emerges at this point, suspension of disbelief; in brief, it is a cognitive function that the recipient of a message, through a specific medium, must undergo in order to accept the represented as real within its context [15]. Games in essence are a combination of mathematical, social, and representational systems. They have their own grammar and boundaries, and that level of complexity must be accounted for when using or designing a game for educational purposes [16]. The goal of the game presented in this work is raising awareness on matters of flood management 
as well as giving a more nuanced perspective, thus, more emphasis should be given to the social and representational systems of the game and the mathematical one plays a supporting role [17-19]. For this reason, the genre chosen was role-playing games (or RPGs), in which, players can take up personas, different from themselves, and act in simulated environments; in this case the simulated environment is a real place that is bound to be flooded. As suggested by the literature, flood management can be gamified through the subgenre survival games in which the players must persevere through a harsh situation [20]. It is important to state that the game world is not fixed to the simulation, but the simulation will act as a flexible narrative device, which challenges the players. At this point, the place of the game master must be stated: the one who interprets the model, catering the narrative to the players [21]. In this case, the survival aspects of the game are not explicitly revealed to the player, but given the disastrous nature of floods, most players will end up engaging with the game through a mode of play that can be described as urban survival. Considering this, there is a need for spatial and temporal consistency while the narrative escalates, which can be achieved by incorporating non-diegetic parts in the game structure. A map resulting from a numerical model simulating the area of the game from existing data was also used. This map showed how the phenomenon would have unfolded, giving the game a sense of realism, which both acts as a storytelling device and as a representation of an event they might be asked to cope with in the future but through an experiential lens [22]. The experiential part comes from the state of the players in the game; they are not expected to give any real solution while playing. Instead, they take on roles in the community that faces said disaster. Through their interactions, while playing, either by discussing with each other, or by adding a part to the narrative, they initially come to their own conclusions and then, as a group, through a free-form discussion, reach a final common one. This mode of play requires not only a certain amount of suspension of disbelief but also a constant engagement of the player during the play session.

\subsection{Engagement, Storytelling, and Reward Systems}

Games fulfil three basic psychological needs: autonomy, competence, and relatedness; game structure should be implemented properly to cover all three [23]. Having established why this game structure fits this educational exercise, the next step before its implementation is to figure out how to keep the player engaged during the whole session. The standard method for achieving engagement in RPGs is through rewards. For example, in the iconic tabletop RPG, Dungeons and Dragons, rewards come in form of gold, trinkets, or experience which are consequential to the characters, or the continuation of the story. Such a method of rewarding in this game is at least counterproductive because of the game mechanic and time intensity that is required. Other games use rewards systems that include badges, leaderboards, progress bars, or in game transactions, but such systems can deter from the goals of the game [24]. The existence of a reward system hints at a desired mode of play, which guides the player to act in a deliberate manner or perhaps breaking their character for a reward that does not provide anything other than a momentary spike in interest $[25,26]$. The aforementioned studies regarded the explicit rewards within the game system, although there is another type of reward that has a more implicit nature and comes from the player interacting with the world and achieving some intrinsic goals set by the player for the character, in essence, a deep state of role-playing. This is quite hard to accomplish without the added constraints of the 3-h session/lecture and the varying levels of game literacy among players, although immersion can be established through interactivity with both the game world and players via the gameplay loop. The suggested gameplay loop consists of seven steps of a circular process of empathy, as described by a previously published work [27], with the goal of creating and overcoming personally set challenges when identifying with a character. In this work, due to the means used, the gameplay loop was deliberately more abstract; observing, assigning meaning, and imaging happened in each player while conversing with the game master, then a certain perspective 
was taken by each player internally, which caused an emotional reaction (feeling and understanding), and finally acting.

\section{Materials and Methods}

\subsection{Basic Concepts}

A game is defined by the Merriam-Webster dictionary as "a physical or mental competition conducted according to rules with the participants in direct opposition to each other". Based on that, in order for a game to exist there must be participants and a complete set of rules dictating the actions of the participants.

In RPGs, the participants are of two kinds, the players who perform the roles and the game master, who is the one responsible for the enforcement of the rules and the general flow of the game. This includes the story, descriptions and, in general, anything that is required for the game to be playable. The most accurate way of approaching the concept of the role in a role-playing context is as "a personal set of rules" for each player. In the same way that an actor follows the script of a play, but there is always room for improvisation, the players of an RPG have their set of rules, but there is also always room for improvisation because of the innate story telling nature of role-playing games.

The players operate in two different levels in the game narrative. The first is the level of the role in which they act and react to actions of other players or the environment created by the game master. The second is the level in which they experience the story as audience; in this separation lies the potential for an interactive method of teaching [17]. The players have preconceived expectations for the situation they will face, but the roles they will perform subverts them, as they are forced to examine the situation from a point of view quite different from their own [19].

In this work, the game master was deliberately a student, having participated in the class the previous year and familiar with the concepts explored. This selection took away the anxiety students might have had with the professor as the game master. Since the game master has a facilitating role, it was better to have in that post a person who was trusted by and not intimidating to the participants [28].

\subsection{Role Playing within the Classroom and the Water Resources Management Class}

The differentiating element in gamification from other modes of teaching is the inclusion of a gameplay aspect in the teaching process. Thus, it is apparent that the success of a gamified lesson, lies in its capability of engaging the player/learners with the game mechanics, which are designed to convey the essence of said lesson or subject. The main questions arising from that statement are "What are the game mechanics?" and most importantly "How and within what context are they used?".

In this case, the game was a tabletop-like role-playing game, played in class but in a teleconference meeting. Initially, this setting suggested some setbacks, such as the lack of physical personal interaction, which is crucial in RPGs, and more importantly how the information flow could be streamlined so that the participants could consistently follow the game narrative and the actions of each player. The game setting was tied to a real place and the narrative took place within a certain timeframe; the digital interface was designated to be a map of said location as a tableau. This decision served two purposes: firstly, a map can easily define the space and scope of the location, making basic information known to everyone in-game easily accessible, so that a pace can be kept, and secondly, from a narrative perspective, the specific location can be imagined by the players with the help of the game master, helping them to suspend their disbelief. In addition to the map, the players were handed out role cards, giving open ended statements, which acted as shorthand or provide special information for each character, for example, a farmer's card had a statement such as "Your farm is outside the town limits" or a tourist's card had a statement such as "You are not able to speak the local language". This enabled the players to freely act out their characters within the constraints of the given role, thus, feeling a personal attachment to the game narrative. 
The play session took place at the last lecture of a thirteen-lecture course regarding water resource management. Throughout the semester, the students had been acquainted with theoretical approaches regarding the subject while working on a project based upon the model WEAP. Evidently all participants had some preconception regarding the matter of flood risk and management as it has been addressed in past lectures, but the approach was resource-oriented, whereas the game was directed towards disaster aversion. The participation was voluntary from the students who had taken the course (four males including the game master and five females, with an age range of 20-23).

\subsection{Gameplay}

The game narrative consisted of three acts, a set-up, a climax, and a resolution; this basic storytelling structure helped the players keep track of all the events that occurred and conveyed a clear story that they could ponder. In the first act, each player introduced their character and gave the group a small description of their daily routine. This acted as world-building and, in turn, familiarized the players with the in-game reality of their situations. The second act described the escalation of the flood event and lasted the better part of the session, as it was the part that required most of the player action. The third act resolved the storylines that manifested and concluded with a general synopsis, which led to the discussion part, where a small debriefing took place. Each act was considered a turn, in which each player conversed with the game master, the game master began to describe their situation, the player took some time to think and plan his/her course of action; after that, the game master described the outcomes of said action in tandem with the current state of the flood. The conversation can follow a nonlinear escalation should a player be unsure of her/his action or need more time to think.

\section{Results}

The results of this work focused on mainly two questions:

- Was the game able to raise awareness of the complexity of the issue?

- How did the participants evaluate this experience in comparison to a traditional lecture?

To answer the first question, two questionnaires were created and given to the participants, one before and one after the RPG. The web-based Mentimeter software was used in this instance to capture the participants' responses. Some questions were similar to assess if there was a change in the participants' opinions. To answer the second question, the participants were asked to evaluate this experience and express if they would like to take part in more similar actions during their studies.

\subsection{Actual Play-Case Study}

In this case study, there were seven participants, one of them had taken part in the creation of the game and was the game master, the other six were part of the class. The roles distributed were the mayor of the town, an elderly citizen, a homeless citizen, a tourist, an employee with children, and a restaurant owner. The game master in this case had a facilitating role, which means that this role was focused on conveying information in a clear manner and helping the players define their roles before they acted. The game master's remarks were always short, and focused on setting the scene, rather than forcing specific actions by the players. An initial ice-breaker phase, where the game master was slightly more talkative, helped relax the players and eliminate anxiety.

\subsubsection{Act 1}

At the beginning of act one the game master set the scene and told the participants that a severe storm was due according to meteorological forecasts. Then, they asked each participant their thoughts, and if they were informed about it, given their role. The player with the tourist role said that they were not informed about the storm and decided to take a stroll to the beach and then go shopping. The restaurant owner was initially reluctant to open the restaurant but, given that it was late spring and the financial loss would be 
significant, decided otherwise. The homeless citizen was totally unaware of the upcoming storm but had observed that the weather was about to change. The elderly citizen, who also faced mobility issues, was partially informed but insisted on continuing with the standard daily routine, which consisted of spending the morning in the local cafe. The employee worked as a waiter at the restaurant owned by the other participant; the employee had two children, one that attended school and one that was at nursing age, and was quite unnerved by the approaching storm but was forced by the restaurant owner to go to work. The mayor of the town was informed of the storm but greatly underestimated the severity of the situation, so they decided not to take any action.

\subsubsection{Act 2}

The restaurant owner decided to open the restaurant but use half of the employed personnel. The tourist took a stroll through town, had brunch, and because of the approaching clouds decided to stay at the hotel. The homeless citizen asked passersby for more information but was unsuccessful in finding out what was going on. The employee was allowed to stay at home, decided to keep their children at home, and was continuously watching the news in order to keep track of the phenomenon or orders given to citizens. The elderly person, given their mobility issues, walked slowly to the cafe and stayed there until noon.

Around 11 am it started raining. The tourist stayed at the hotel the whole day and was safe throughout the whole day. The restaurant owner gathered the clients at the interior of the restaurant. The employee remained at home. The mayor did not take any actions and was assured that it was just a storm. The homeless citizen found shelter in the restaurant.

At 12 p.m., the river basin that goes through town started filling up, and some roads had rainwater flowing through them. The clients of the cafe including the elderly person were stuck at the cafe and made calls for someone to take them home, but no one was available. The employee alerted the fire brigade.

\subsubsection{Act 3}

At 1 p.m., part of the town flooded, as well as the cafe and the basement of the house of the employee, and part of the electric grid was damaged nearby so those places lost electricity. At the restaurant, water started flowing into the premises, and the owner tried to keep the clients safe. Three fire trucks were deployed, but one of them was overturned because of the high-water flow at a crossing; no one was harmed.

\subsubsection{Discussion among Participants}

The players discussed their strategies, mainly, what they could have done in order to keep being safe given each one's condition and what caused them eventually to be endangered. They came to the following conclusions:

- $\quad$ Properly informing the public is important in order to keep people safe.

- When facing extreme phenomena, it is important to take precautions both as individuals and as a community.

- Everyone in the community is affected by such events, and the material damages from those kinds of events are high.

- When facing said disasters, individual actions are inadequate, and the governing bodies should coordinate the public and are able to provide precautionary measures, which lessen the impact of a disaster.

Then, a discussion followed, with an invited expert in flood management where students asked questions that they came up with while playing about what can be done in this situation. All players were eager to ask questions of the expert, and the discussion was probably much more interactive than in a traditional classroom with an invited speaker. 


\subsection{Evaluation-Mentimeter Results}

\subsubsection{Pre-RPG Questionnaire}

The pre-RPG questionnaire was conducted immediately before the play session. Question 1 Pre-RPG-What keyword(s) does the term "flood" evoke for you?

Damage(s) was the most common answer along with water, storm, drowning, problem, Noah, and overflow. The answers show the inclination of engineering students to focus on the technical aspects of the phenomenon and not on the social ones.

\section{Question 2 Pre-RPG-What is affected by a flood?}

Some answers focused on one thing such as plantations, others on more aspects including houses, human lives, soil, water quality, and quality of life. This more specific phrasing of the question invoked answers with the social aspect into the foreground.

Question 3 Pre-RPG-How probable is it for one of the following to be impacted by a flood, and how severe will that impact be?

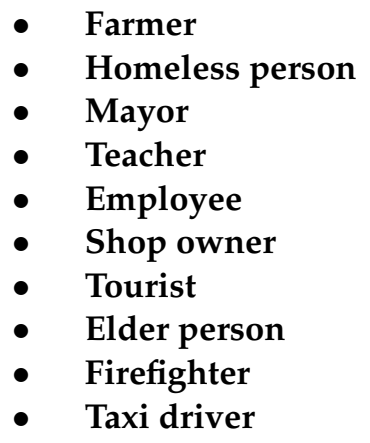

The answers to this question before the RPG game, depicted in Figure 1, focused on people often impacted by adverse effects of floods, such as farmers and homeless people. In general, all the responses were medium-high, since the scale had a range from -5 to 5 with -5 being impossible and negligible and 5 being certain and very severe, respectively. The average of the responses was for all roles above zero, for both probability and severity. The least expected to be affected were the tourist, the employee, and the teacher. It is interesting to note that only a handful of answers were slightly towards unlikely or small impact.

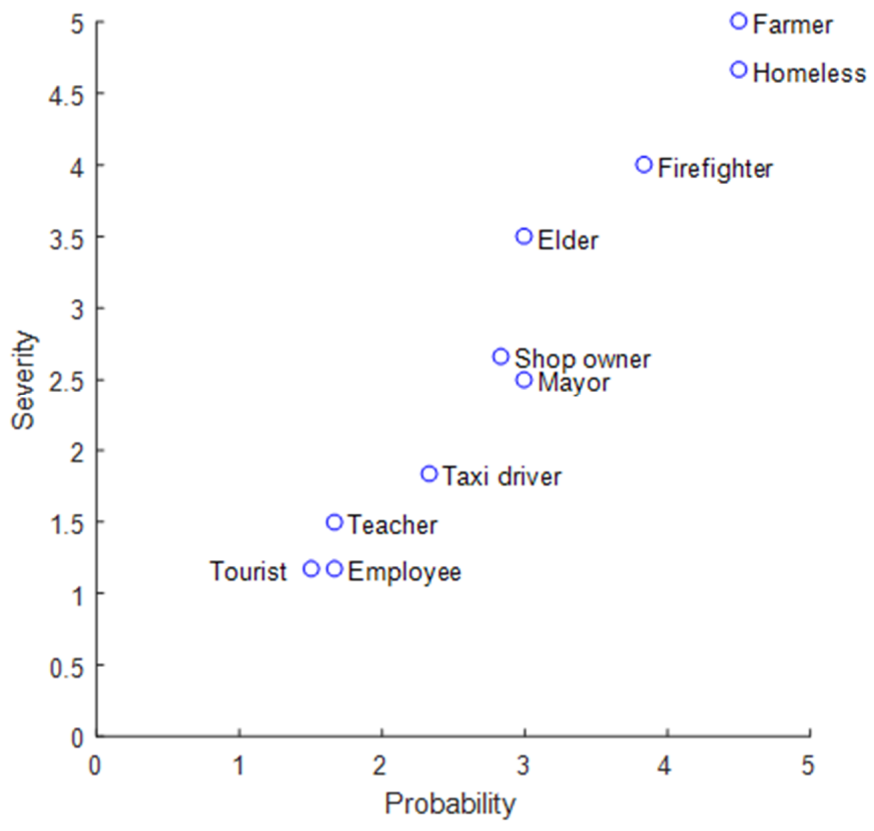

Figure 1. Probability and severity of being affected by a flood event for different roles according to the participants before the RPG game. 


\subsubsection{Post-RPG Questionnaire}

The post-RPG questionnaire was conducted immediately after the play session.

\section{Question 1 Post-RPG-What is affected by a flood?}

After the RPG, the answers in this question changed a bit, and included the economy, everything, and the whole society that lives in the region. They still included the technical aspects such as infrastructure, property, and human lives. This was a first sign that, during the RPG, students had the opportunity to understand the complex nature of such an event and the many ways it can affect and disrupt everyday life.

Question 2 Post-RPG-How probable is for one of the following to be impacted by a flood and how severe will that impact be?

\section{- Farmer \\ - Homeless \\ - Mayor \\ - Teacher \\ - Employee \\ - Shop owner \\ - Tourist \\ - Elder \\ - Firefighter \\ - Taxi driver}

The answers to this question, depicted in Figure 2, also changed after the RPG game with generally higher scores for the majority of people in the question. Interestingly, both the employee and teacher probability and severity increased, which suggests that the respondents' view of the flood impact changed, maybe more so for roles that appeared in the game. The taxi driver for example, who was not an active role in the game, was one of the least expected to be severely affected by the flood. However, the person who was expected by the respondents to be the least affected by a flood was the tourist, something that might be attributed to the cautious attitude that the player of the specific role had during the game. They were careful enough not to take any chances and stay safe in the hotel instead of going sightseeing during the storm.

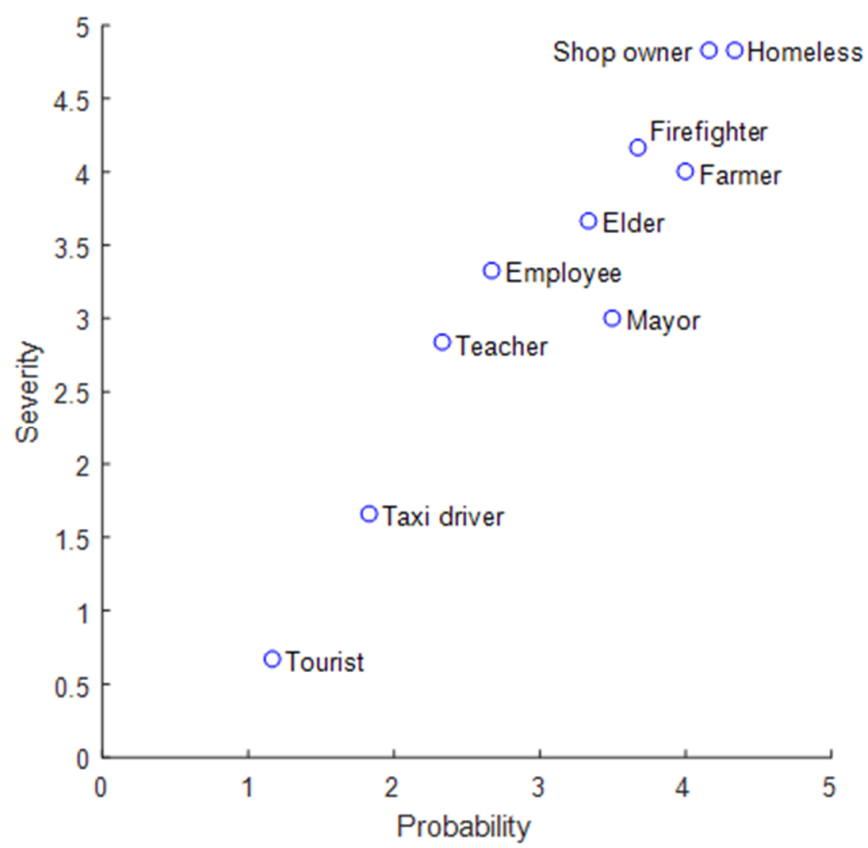

Figure 2. Probability and severity of being affected by a flood event for different roles according to the participants after the RPG game. 
The most significant changes were in the severity for the employee and the shop owner (+2.2 increase), and to a lesser degree for the teacher $(+1.3)$ and the mayor $(+0.5)$. The changes in probability followed a similar pattern, with lower values $(1.3,1,0.7$ and 0.5$)$ for shop owner, employee, teacher, and mayor, respectively.

\section{Question 3 Post-RPG-What is your takeaway from this game?}

The main takeaway for most of the respondents was that prevention plays an important role, and checking the weather is significant. Many answers included that the game made them think and care more, which was exactly the intention when creating it.

\subsubsection{Students' Comments and Feedback}

Finally, feedback was asked for further improvement of the game in a future iteration, with the results shown in Figure 3. Concerning the organization, no problems were reported, and the guidance was highly evaluated. Concerning the media and material used, everyone thought they were easy to understand, interesting, and helpful, which shows that the approach of not over-explaining and leaving space for the players to build their in-game characters closer to a personality of their liking, did not make them feel lost, or poorly informed. The feedback concerning how useful they found this action as a way of learning was very encouraging, and the willingness to participate in more similar actions during their studies was also very high.

\begin{tabular}{lr} 
This action was well organized & 4.5 \\
\hline Materials were understandable & 4.8 \\
\hline Materials were useful & 4.5 \\
\hline Materials were helpful & 4.5 \\
\hline Organizers guided us correctly & 4.7 \\
\hline & \\
\hline & \\
\hline & \\
\hline & \\
\hline
\end{tabular}

Figure 3. Feedback on the action from the participants on a scale from -5 (completely disagree) to 5 (completely agree).

\section{Conclusions}

In role-playing games, suspension of disbelief is important among players to start engaging in their in-game role. In this work, simple visual and technical effects were used, which achieved a good level of suspension of disbelief, with players engaging enthusiastically. Simple to produce maps or results of a basic hydraulic model were adequate to give the participants the necessary information concerning the status of the scene. Engagement of players can be provoked and maintained by a carefully planned storyline that allows them to feel included in the story and able to modify the results through their actions/decisions.

Mixing new ways into university teaching such as an RPG can help students engage more and put themselves in different situations. The feedback from the students showed that these forms were appreciated and welcomed by them. Learning by doing can be a formidable tool for understanding, especially complex concepts such as flood risk and flood management. An index of the success of this endeavor was the discussion that followed after the play session. The students not only posed nuanced and refined questions, but while conversing they had a constructive discussion, which according to the professor, 
happened less frequently in traditional lectures. In addition, the students raised questioned on matters that were not implicitly stated in-game, which means that after the game session, they were more able to think abstractly about the subject as well as implement ideas from past lectures. This approach can easily be transferred for use in different environments, where awareness-raising among different stakeholders is the goal, although it is important to keep in mind that this educational process is about understanding a subject and cannot replace a standard lecture at least at the academic level. When applying it to a community or a stake holder meeting it is important to have a small briefing introduction to the key concepts that are explored in-game.

Using the RPG in a less constrained way, without explicitly telling players how to act under certain circumstances helps them think more about their in-game characters and how they would react in certain circumstances. This is far better than forcing the participants to predetermined reactions based on a specific script and did not diminish the opportunity of the organizers to guide the participants.

The participants after this RPG were able to better identify the stakeholders who a flood event affects. They noted that the probability and severity of this effect was higher than what they thought before the game. It is notable that the player with the role of mayor said that, in the beginning, they tried to think in a rational way in order to face the flood threat, but during the game they made a list of decisions and actions, that if they were taken on time, the situation would be completely different in the end. They also insisted on the significance of public awareness and especially of the timely information of stakeholders who are directly affected from a flood due to their daily routine. Finally, it is worth noting that students found that RPGs help to understand better a problem, they suggested that similar actions could take place for other topics, i.e., fires, or for the awareness of the public about wind turbines on the islands, which today is also a hot environmental management topic.

Author Contributions: Conceptualization, F.S., I.T. and A.-E.V.; Investigation, F.S.; Methodology, F.S. and A.-E.V.; Resources, F.S.; Supervision, I.T.and A.-E.V.; Visualization, I.T.; Writing—original draft, F.S.; Writing-review \& editing, I.T. and A.-E.V. All authors have read and agreed to the published version of the manuscript.

Funding: Not applicable.

Institutional Review Board Statement: The study was conducted according to the guidelines of the Declaration of Helsinki, and approved by the Institutional Review Board of the Joint Research Centre, European Commission (protocol code JRC127482 and date of approval 9 December 2021).

Informed Consent Statement: Informed consent was obtained from all subjects involved in the study.

Data Availability Statement: Not applicable.

Acknowledgments: The authors would like to thank the participants of this RPG: Chatziprodromou Vasiliki, Iliopoulos Ilias, Konstantoudakis Evangelos, Mato Giolanta, Papa Kalliopi-Mikaela Papailiou Ioannis, and Sotiriou Maria-Anna. Their constructive dialogues, effective thoughts, and significant comments formed the input and output of this work.

Conflicts of Interest: The authors declare no conflict of interest.

\section{References}

1. Meera, P.; McLain, M.L.; Bijlani, K.; Jayakrishnan, R.; Rao, B.R. Serious Game on Flood Risk Management. In Emerging Research in Computing, Information, Communication and Applications; Shetty, N.R., Prasad, N.H., Nalini, N., Eds.; Springer: New Delhi, India, 2016; pp. 197-206, ISBN 978-81-322-2552-2.

2. Khoury, M.; Gibson, M.J.; Savic, D.; Chen, A.S.; Vamvakeridou-Lyroudia, L.; Langford, H.; Wigley, S. A Serious Game Designed to Explore and Understand the Complexities of Flood Mitigation Options in Urban-Rural Catchments. Water 2018, $10,1885$. [CrossRef]

3. Novia, W. Kusumaningrum; Madlazim; Tarzan Purnomo Development of OrSAEv Model Learning Materials Based on RolePlaying of Against Flood Disaster Mitigation Preparedness, Anxiety and Enjoyment of Junior High School. IJORER Int. J. Recent Educ. Res. 2021, 2, 171-183. [CrossRef] 
4. Belova, N.; Eilks, I.; Feierabend, T. The Evaluation of Role-Playing in the Context of Teaching Climate Change. Int. J. Sci. Math. Educ. 2015, 13, 165-190. [CrossRef]

5. Bilro, R.G.; Loureiro, S.M.C.; de Aires Angelino, F.J. The Role of Creative Communications and Gamification in Student Engagement in Higher Education: A Sentiment Analysis Approach. J. Creat. Commun. 2021, 097325862199264. [CrossRef]

6. Terti, G.; Ruin, I.; Kalas, M.; Láng, I.; Cangròs i Alonso, A.; Sabbatini, T.; Lorini, V. ANYCaRE: A Role-Playing Game to Investigate Crisis Decision-Making and Communication Challenges in Weather-Related Hazards. Nat. Hazards Earth Syst. Sci. 2019, 19, 507-533. [CrossRef]

7. Agusdinata, D.B.; Lukosch, H. Supporting Interventions to Reduce Household Greenhouse Gas Emissions: A Transdisciplinary Role-Playing Game Development. Simul. Gaming 2019, 50, 359-376. [CrossRef]

8. Lebel, P.; Sriyasak, P.; Kallayanamitra, C.; Duangsuwan, C.; Lebel, L. Learning about Climate-Related Risks: Decisions of Northern Thailand Fish Farmers in a Role-Playing Simulation Game. Reg. Environ. Chang. 2016, 16, 1481-1494. [CrossRef]

9. Huyakorn, P.; Denpaiboon, C.; Kanegae, H. Role-Play Gaming Simulation for Flood Management on Cultural Heritage: A Case Study of Ayutthaya Historic City. Int. J. Humanit. Soc. Sci. 2012, 6, 6.

10. Salvini, G.; van Paassen, A.; Ligtenberg, A.; Carrero, G.C.; Bregt, A.K. A Role-Playing Game as a Tool to Facilitate Social Learning and Collective Action towards Climate Smart Agriculture: Lessons Learned from Apuí, Brazil. Environ. Sci. Policy 2016, 63, 113-121. [CrossRef]

11. Magnuszewski, P.; Królikowska, K.; Koch, A.; Pająk, M.; Allen, C.; Chraibi, V.; Giri, A.; Haak, D.; Hart, N.; Hellman, M.; et al Exploring the Role of Relational Practices in Water Governance Using a Game-Based Approach. Water 2018, 10, 346. [CrossRef]

12. Edwards, P. Tools for Adaptive Governance for Complex Social-Ecological Systems: A Review of Role-Playing-Games as Serious Games at the Community-Policy Interface. Environ. Res. Lett. 2019, 14, 113002. [CrossRef]

13. Medema, W.; Mayer, I.; Adamowski, J.; Wals, A.E.J.; Chew, C. The Potential of Serious Games to Solve Water Problems: Editorial to the Special Issue on Game-Based Approaches to Sustainable Water Governance. Water 2019, 11, 2562. [CrossRef]

14. Kalogiannakis, M.; Papadakis, S.; Zourmpakis, A.-I. Gamification in Science Education. A Systematic Review of the Literature. Educ. Sci. 2021, 11, 22. [CrossRef]

15. Brown, D.W. The Suspension of Disbelief in Videogames. Ph.D. Thesis, School of Arts, Brunel University, London, UK, 2012.

16. Filipe, E.P.R. Harnessing Interactive Media Ideological Power: A Disempowerment Model for Video Games. In Proceedings of the Play2Learn, Lisbon, Portugal, 19 April 2018; CICANT: Lisbon, Portugal, 2018; pp. 333-349, ISBN 978-989-757-068-1.

17. Cheville, R.A. Linking Capabilities to Functionings: Adapting Narrative Forms from Role-Playing Games to Education. High Educ. 2016, 71, 805-818. [CrossRef]

18. Aubert, A.H.; Medema, W.; Wals, A.E.J. Towards a Framework for Designing and Assessing Game-Based Approaches for Sustainable Water Governance. Water 2019, 11, 869. [CrossRef]

19. Den Haan, R.-J.; van der Voort, M. On Evaluating Social Learning Outcomes of Serious Games to Collaboratively Address Sustainability Problems: A Literature Review. Sustainability 2018, 10, 4529. [CrossRef]

20. Woolbright, L. Game Design as Climate Change Activism. Alenda Chang. John Parham. Ecozon 2017, 8, 15.

21. Klempous, R.; Nikodem,, J.; Baranyi, P.Z. (Eds.) Cognitive Infocommunications, Theory and Applications; Topics in Intelligent Engineering and Informatics; Springer International Publishing: Cham, Switzerland, 2019; Volume 13, ISBN 978-3-319-95995-5.

22. Khan, T.A.; Zhao, X. Perceptions of Students for a Gamification Approach: Cities Skylines as a Pedagogical Tool in Urban Planning Education. In Responsible AI and Analytics for an Ethical and Inclusive Digitized Society; Dennehy, D., Griva, A., Pouloudi, N., Dwivedi, Y.K., Pappas, I., Mäntymäki, M., Eds.; Lecture Notes in Computer Science; Springer International Publishing: Cham, Switzerland, 2021; Volume 12896, pp. 763-773, ISBN 978-3-030-85446-1.

23. Manzano-León, A.; Camacho-Lazarraga, P.; Guerrero, M.A.; Guerrero-Puerta, L.; Aguilar-Parra, J.M.; Trigueros, R.; Alias, A. Between Level Up and Game Over: A Systematic Literature Review of Gamification in Education. Sustainability 2021, $13,2247$. [CrossRef]

24. Giakalaras, M.M. Gamification and Storytelling. Univ. Aegean 2016, 8, 1-7.

25. Kim, J.; Castelli, D.M. Effects of Gamification on Behavioral Change in Education: A Meta-Analysis. Int. J. Environ. Res. Public. Health 2021, 18, 3550. [CrossRef]

26. Nicholson, S. A RECIPE for Meaningful Gamification. In Gamification in Education and Business; Reiners, T., Wood, L.C., Eds.; Springer International Publishing: Cham, Switzerland, 2015; pp. 1-20, ISBN 978-3-319-10207-8.

27. López-Faican, L.; Jaen, J. Designing Gamified Interactive Systems for Empathy Development. In Proceedings of the Companion Publication of the 2021 ACM Designing Interactive Systems Conference, Virtual Event, New York, NY, USA, 28 June 2021.

28. Aubert, A.H.; Bauer, R.; Lienert, J. A Review of Water-Related Serious Games to Specify Use in Environmental Multi-Criteria Decision Analysis. Environ. Model. Softw. 2018, 105, 64-78. [CrossRef] 